\title{
Controlar os militares? \\ Uma análise da dimensão de accountability sobre a atuação doméstica das Forças Armadas no Brasil
}

\author{
Control the military? \\ An analysis of the accountability dimension on the \\ domestic employment of the Armed Forces in Brazil
}

Rev. Bras. Est. Def. v. 6, $\mathrm{n}^{\circ} 1$, jan./jun. 2019, p. 51-77

DOI: 10.26792/RBED.v6n1.2019.75120

ISSN 2358-3932

\section{ANAÍS MEDEIROS PASSOS}

Quem guarda os guardiães? ${ }^{1}$ A pergunta, atribuída ao poeta Juvenal, nos versos Sátira IV, permanece atual. Como equilibrar a existência de um Exército, forte o suficiente para assegurar a defesa do território, porém subordinado institucionalmente ao Poder Executivo? Sob um regime democrático, o paradoxo torna-se mais evidente. Nesse caso, existe uma tensão entre o exercício da soberania territorial, a partir da defesa militar das fronteiras nacionais, e a dimensão de accountability, que é característica dos regimes democráticos. ${ }^{2}$ De que forma equilibrar a garantia do monopólio territorial, a qual exige a eficiência dos militares no cumprimento de tal missão, e a necessidade de que estes prestem contas das suas atividades às autoridades políticas e, de maneira mais ampla, à sociedade?

Tais perguntas assumem relevância considerando a crescente participação dos militares na manutenção da segurança pública em diferentes regiões do globo, incluindo os Estados Unidos, a Europa e a América Latina (Kappeler and Kraska 2015; Diamint 2015; Guittet 2006). Nesse contexto, cabe indagar como essas políticas públicas do tipo coercitivas (Hassenteufel 2014) podem impactar sobre a qualidade dos sistemas políticos democráticos. Considerando essas questões, esse artigo tem o objetivo de caracterizar o nível de controle civil exercido sobre os militares em ação, a partir

Anaís Medeiros Passos - Pós-Doutoranda no Instituto de Relações Internacionais da Universidade de São Paulo (IRI-USP), sendo bolsista da Coordenação de Aperfeiçoamento de Pessoal de Nível Superior (PNPD CAPES) e membro do Núcleo de Pesquisa em Relações Internacionais (NUPRI). Doutora em Ciência Política, associada ao Centre de Recherches Internationales (CERI) da Sciences Po Paris, e mestra em Ciência Política pela Universidade Federal do Rio Grande do Sul (UFRGS). 
da análise das operações para a garantia da lei e da ordem (GLO) na cidade do Rio de Janeiro (2010-2015).

Essas operações duraram entre um ano e três meses e um ano e meio, abrangendo um contingente composto por 1,800, no caso da operação GLO que ocorreu nos Complexos do Alemão e da Penha, e por 2,500 militares, no caso da operação GLO empregada no Complexo da Maré (de Lima 2012). A chamada Força de Pacificação atuou exclusivamente em missões de patrulhamento ostensivo e prisão em flagrante delito nos conjuntos de favelas localizados na região norte da cidade do Rio de Janeiro: o Complexo do Alemão, o Complexo da Penha e o Complexo da Maré. Enquanto as duas primeiras localidades são dominadas pelo Comando Vermelho (CV), a Maré é uma área de disputa entre o CV, o Terceiro Comando Puro (TCP), os Amigos dos Amigos (ADA) e grupos da milícia.

$\mathrm{O}$ fato de esses locais serem caracterizados pela predominância de grupos não-estatais criminais cria situações de instabilidade para os moradores, os quais convivem com a violência de maneira rotineira. Em outubro de 2010, a cidade do Rio de Janeiro foi palco de uma série de ataques incendiários a ônibus e a veículos particulares. A polícia militar do estado do Rio de Janeiro atribuiu esses ataques ao Comando Vermelho, que à época estaria "instalado" nos Complexos da Penha e do Alemão."

Por sua vez, a segunda operação, que iniciou em abril de 2014, foi realizada de maneira preventiva, visto que o Complexo da Maré é um conjunto de favelas que circundam a Avenida Brasil - passagem obrigatória para os turistas que chegam ao Aeroporto Internacional Tom Jobim (Passos 2018). No limiar entre a guerra e a paz, o emprego de militares, dentro das fronteiras nacionais, levanta preocupações a respeito dos possíveis entraves que o mesmo pode gerar para a consolidação da democracia no Brasil. Em última instância, as limitações para o exercício de accountability refletem o que Guillermo O’Donnell denominou “áreas marrons”, nas quais predomina uma distribuição desigual do estado de direito (O’Donnell 1993).

$\mathrm{O}$ artigo divide-se em três seções. Primeiro, descreve o escopo teórico que orienta a pesquisa, apresentando uma definição de controle civil que abrange todas as fases de uma operação militar: antes, durante e depois. A seguir, caracterizamos o exercício do controle civil no Brasil, do ponto de vista das instituições federais. Na terceira seção, o artigo analisa de que maneira as instituições de controle atuam durante as operações para a garantia da lei e da ordem, buscando identificar o reflexo dos incentivos distintos dessa configuração institucional sobre o comportamento dos membros das instituições militares fora dos quarteis. 


\section{NOTA METODOLÓGICA}

O presente artigo foi realizado a partir da pesquisa de campo que foi conduzida pela autora entre os anos de 2016 e 2017. No contexto da sua pesquisa de doutorado, foram realizadas 50 entrevistas semiestruturadas nas cidades do Rio de Janeiro, de São Paulo e de Brasília com atores envolvidos no processo decisório e na implementação da política em questão. Além disso, foram analisados documentos oficiais relacionados às operações para a garantia da lei e da ordem, incluindo manuais de regras de engajamento e extratos de acordos entre o governo do estado e o Ministério da Defesa que definem as condições de emprego da Força de Pacificação.

O perfil dos entrevistados incluiu oficiais das Forças Armadas de patente média e alta, ministros da Defesa, burocratas civis, policiais, membros de organizações de direitos humanos, membros do Poder Judiciário e moradores de favelas nas quais houve operação militar (incluindo líderes comunitários). O roteiro de entrevistas abrangeu questões sobre o processo decisório, a implementação da missão, a negociação das condições de emprego, a relação entre militares e associações de moradores e a percepção da população sobre a atuação dos militares.

Posteriormente, as entrevistas foram transcritas integralmente e analisadas utilizando o Software NVivo. Para a análise das entrevistas, foi empregada uma estratégia mista para a elaboração de códigos (middle-range category) extraídos da revisão da literatura sobre relações civis-militares, ou elaborados de maneira indutiva a partir da análise de dados primários. No último ponto, utilizou-se uma teoria fundamentada nos dados (Urquhart 2017), que permitiu estabelecer uma relação entre os códigos através de um processo indutivo e, posteriormente, formular uma explicação teórica para a relação identificada, quando a mesma não estava clara utilizando a teoria existente. Além disso, empregou-se a triangulação do conteúdo das entrevistas com outras fontes, incluindo jornais e processos legais.

No caso desse artigo, foram analisadas categorias sobre "ministério da defesa", "controle civil”, "sociedade civil" e "protestos". As entrevistas permitiram incorporar uma análise do funcionamento dos diferentes mecanismos (ou a ausência dos mesmos) que visam a subordinar os militares às autoridades políticas e aos civis durante uma operação militar. Nesse sentido, buscou-se levar em conta não apenas as instituições de controle civil, mas também os atores e os grupos da sociedade civil que exercem algum tipo de vigilância ou denúncia sobre a ação dos militares nas favelas quando existem desvios de comportamento. A definição de controle civil adotada no trabalho, que engloba as fases antes, durante e após a intervenção militar, responde a essas preocupações empíricas que surgiram a 
partir da análise das entrevistas. Na próxima seção, aprofundamos o marco teórico que embasa esse artigo.

\section{CONTROLE CIVIL E ACCOUNTABILITY SOBRE OS MILITARES}

Entre o final dos anos 1970 e o começo dos anos 1980, os regimes autoritários na América do Sul, Ásia e África foram gradualmente desmantelados, constituindo o que Samuel Huntington definiu como "terceira onda de democratização” (Huntington 1991). No Brasil, a transição democrática foi concluída oficialmente em 1985, com a realização das eleições indiretas para a Presidência da República. Esse evento pôs fim a um regime civil-militar que governou o país por 21 anos (1964-1985). Não obstante, a troca de regime levantou preocupações sobre a capacidade de consolidação das recém-estabelecidas democracias frente ao passado autoritário.

Robert Dahl desenvolveu o termo poliarquia para designar a consecução empírica do ideal tipo democrático a partir de um conjunto de critérios normativos (Dahl 1973, 3). É importante notar que a definição procedimental de democracia proposta por Robert Dahl assume que as políticas governamentais devem depender exclusivamente do voto, em lugar de terceiros, como a Igreja, os empresários e as Forças Armadas (Schmitter and Karl 1991, 76).

Nesse sentido, a literatura que analisou as transições políticas levadas a cabo na América Latina ao longo do final dos anos 1980 e 1990 compartilha uma preocupação normativa pelo estabelecimento e pela consolidação do controle civil sobre os militares em novas democracias (Aguero 1992, 1995; Mainwaring, O’Donnell, and Valenzuela 1992). Mais especificamente, alguns dos objetivos de se submeter os militares à supremacia civil são: proteger os direitos humanos de todos os membros da sociedade, alinhar os objetivos políticos de lideranças civis e militares, legitimar o uso da força por grupos associados ao estado e reduzir os poderes discricionários dos militares (Born 2006, 155).

O debate sobre a sobrevivência das novas democracias foi posteriormente substituído pelas discussões sobre a qualidade do regime político que estava em vias de consolidação (Diamond et al. 1997). Atualmente, alguns autores enfatizam a existência de regimes híbridos que combinam traços herdados dos regimes autoritários com o aprimoramento da dimensão eleitoral (Geisser, Dabène and Massardier 2008; Garreton 1989). Cabe ressaltar que as relações civis-militares constituem um âmbito ideal para verificar a interseção entre regime democrático e passado autoritário. Nesse caso, existem duas acepções de controle civil, ex-ante e ex-post, que merecem a nossa atenção para uma análise aprofundada da intervenção dos militares na segurança pública. 
Segundo a primeira concepção, a ideia subjacente é que a configuração específica depende de um acordo sobre a distribuição de poder selado entre autoridades civis e militares (Mares 2003, 3141-3142; Pion-Berlin 2001, $521)$. Ou seja, trata-se de uma relação de negociação. Em troca da subordinação política, os militares gozariam de um nível de autonomia considerável para o cumprimento de suas missões constitucionais. Essa definição foi consagrada por Samuel Huntington (1957). Para o autor, assegurar controle civil é tornar a profissão militar "politicamente estéril", porém autônoma no que diz respeito às suas questões corporativas.

Entretanto, no campo da relação entre civis e militares, esse processo enfrenta alguns desafios. Agentes civis e militares, ainda que concordem sobre como assegurar segurança para o Estado, podem discordar sobre os termos específicos para fazê-lo (Feaver 2003). Além disso, a assimetria de informações desempenha um efeito profundo sobre as relações entre civis e militares. O status dos militares como especialistas na administração da violência possibilita vantagens expressivas sobre os civis no acesso à informação nas áreas de tática e logística, as quais tendem a aumentar conforme a operação se aproxima do combate. Essa característica alerta para a importância do estabelecimento de uma rede dinâmica de mecanismos de freios e contrapesos, para além do exercício da subordinação dos militares ao poder presidencial.

Seguindo essa lógica, a segunda concepção de controle civil enfatiza a necessidade de integração dos militares à sociedade (Born 2006; Schiff 2009). Segundo tais autores, o controle civil é uma relação de comando que implica não somente o estabelecimento de controles ex-ante, mas também durante e após a realização de uma determinada atividade militar. Tal objetivo inclui o estabelecimento de freios e contrapesos para monitorar o comportamento dos militares, seja por meio de agências estatais ou da sociedade civil. Argumentamos que essa concepção de controle civil é a mais adequada para o estudo da dimensão de accountability sobre as operações para a garantia da lei e da ordem.

Para a operacionalização do conceito de controle civil, nos basearemos em Bruneau and Matei (2008, 915-917). De acordo com esses autores, o controle civil pode ser verificado através de três aspectos: controle institucional, supervisão e normas profissionais. O controle institucional é exercido principalmente pelo Ministério da Defesa (Fuccille 2006; Bruneau 2001). Quando equipada com recursos materiais adequados e pessoal, a instituição assegura que oficiais militares estão subordinados às decisões das autoridades eleitas a respeito das suas missões.

Supervisão implica que os Poderes Legislativo e Judiciário, assim com a mídia e sociedades da organização civil, rastreiem as ações das Forças 
Armadas, assegurando que isso ocorra de acordo com as determinações das autoridades políticas e/ou sociedade civil. O Poder Executivo, incluindo o Ministério da Defesa, também estão habilitados a desempenhar esse papel. Por último, as regras profissionais definem os procedimentos para o recrutamento, treinamento, promoção e educação de membros das Forças Armadas, assegurando que isso ocorra de acordo com as decisões das autoridades políticas.

Nesse sentido, a categoria controle civil é uma expressão da accountability no campo das relações entre civis e militares. O termo accountability implica uma relação entre o ator e o fórum (a instituição que delega autoridade), no qual o ator possui a obrigação de explicar e justificar a sua conduta. O fórum pode apresentar questões, passar julgamentos, e o ator enfrenta potencialmente consequências no caso de desvios da função que lhe foi atribuída (Bovens 2007). Dessa maneira, Schedler identifica dois processos correlatos no exercício da accountability. A responsividade e a punição, quando necessária, de desvios de condutas ou infrações (Schedler 1999).

Conforme a definição de Mccubins, os chamados alarmes de incêndios (fire alarms) são responsáveis pela monitoria da ação pública no nível local (Kiewiet and McCubbins 1991)however, delegation facilitates the avoidance of blame rather than the taking of credit p. $2 \backslash n \backslash n$ Delegation theory. \&quot; The alternative we pose to the abdication hypothesis is that it is possibl to delegate authority to others and yet continue to achieve desired outcomes\&quot; p. 3 They add that sometimes the desired results can only be achieved by delegating authority p. $3 \backslash n \backslash n$ Delegation entail side effects known as \&quot;agency losses\&quot;. There is almost always some conflict between the interests of those who delegate authority (principals. Por outro lado, a sua principal limitação é que a sua função se restringe a comunicar o evento da violação uma vez que a mesma foi consumada. No caso das chamadas patrulhas de polícia (police patrols), tais mecanismos são incumbidos da função de monitorar, premiar ou punir uma determinada ação, quando ocorrem desvios por parte de agentes do estado. Portanto, essa definição remete à necessidade de analisar o nível de controle civil exercido em todas as etapas da ação militar, desde o processo decisório até a sua implementação.

\section{A CARACTERIZAÇÃO DO CONTROLE CIVIL SOBRE OS MILITARES EM NÍVEL NACIONAL}

As democracias nascentes diferem das democracias mais antigas no que diz respeito ao padrão de controle civil que foi consolidado. Trinkunas (2005, 17-18) observa que existem quatro caminhos para as democracias 
nascentes, os quais dependem das instituições previamente existentes no âmbito da defesa, dos desafios e das oportunidades enfrentadas por aqueles que lideraram o processo de transição. Regimes sob risco facilitam a conservação de esferas de influência política das elites militares no novo regime. Na modalidade de persistência de regime, os governos fornecem certo nível de monitoramento sobre as Forças Armadas, o qual é combinado com táticas de apaziguamento, de maneira a prevenir golpes de estado. As outras duas modalidades de controle civil são contensão e sanção. A contensão é uma tática de "dividir e conquistar", que busca neutralizar as atividades políticas dos militares sem influenciar o seu orçamento e a sua doutrina. Trata-se de um atalho para assegurar a supremacia civil, mas sem alterar de maneira significativa o nível de autonomia militar. Por outro lado, sancionar requer capacidades efetivas das autoridades civis para sustentar os mecanismos de punição, no caso de oficiais militares que não cumprem com as suas decisões. Essa é a situação que melhor ilustra a existência de um controle civil extensivo.

A partir de uma sistemática revisão da literatura sobre controle civil, o Quadro 1 sintetiza as principais categorias que são utilizadas para verificar o nível de controle civil (Trinkunas 2005; Bruneau 2001; Joo 1996), as quais compreendem as normas profissionais, o Ministério da Defesa, o controle legislativo, o controle judiciário e a sociedade civil. Classificamos o controle civil como (1) ausente, (2) limitado ou (3) extensivo. Por sua vez, o Quadro 2 caracteriza o nível de controle civil no Brasil de acordo com essas categorias. Trataremos de justificar essa classificação nos parágrafos seguintes.

O Brasil seguiu uma trajetória de monitoria e apaziguamento que, posteriormente, evoluiu para a sanção civil sobre certas áreas. A transição democrática (1974-1985) foi controladas pelos comandantes militares, os quais mantiveram extensas prerrogativas no novo regime (Zaverucha 1994; Arturi 2001). Algumas das evidências do fraco controle civil sobre as Forças Armadas foram a criação tardia do Ministério da Defesa (1999), em comparação com outros países da América Latina, ${ }^{4}$ e a existência de oficiais militares ocupando posições no gabinete presidencial durante o governo de José Sarney (1985-1990) (Stepan 1988, 104-110). 


\section{Quadro 1}

\section{Categorias para Classificar o Nível de Controle Civil}

\begin{tabular}{|c|c|c|c|}
\hline & 1 - Ausente & 2-Limitado & 3-Extensivo \\
\hline $\begin{array}{l}\text { Normais } \\
\text { Profissionais }\end{array}$ & $\begin{array}{l}\text { Forças Armadas operam } \\
\text { com plena autonomia em } \\
\text { assuntos internos. }\end{array}$ & $\begin{array}{l}\text { Autoridades civis exer- } \\
\text { cem uma influência limi- } \\
\text { tada sobre promoções, } \\
\text { orçamento e doutrina. }\end{array}$ & $\begin{array}{l}\text { As autoridades e a so- } \\
\text { ciedade civil definem e } \\
\text { examinam as promoções, } \\
\text { o orçamento e a doutrina } \\
\text { através de processos pú- } \\
\text { blicos. }\end{array}$ \\
\hline $\begin{array}{l}\text { Ministério da } \\
\text { Defesa }\end{array}$ & $\begin{array}{l}\text { Oficiais militares de alta } \\
\text { patente supervisionam } \\
\text { essa agência. }\end{array}$ & $\begin{array}{l}\text { Civis lideram a insti- } \\
\text { tuição, porém não estão } \\
\text { inseridos no sistema po- } \\
\text { lítico. Falta de recursos } \\
\text { e ausência de assessores } \\
\text { civis para assessorar a } \\
\text { monitoria das Forças Ar- } \\
\text { madas. }\end{array}$ & $\begin{array}{l}\text { Civis lideram a institui- } \\
\text { ção. As Forças Armadas } \\
\text { são representadas por um } \\
\text { comando unificado, exis- } \\
\text { tência de uma carreira de } \\
\text { experto civil em defesa, } \\
\text { ministros possuem recur- } \\
\text { sos para subordinar os } \\
\text { comandantes militares. }\end{array}$ \\
\hline $\begin{array}{l}\text { Controle } \\
\text { Legislativo }\end{array}$ & $\begin{array}{l}\text { As Forças Armadas são } \\
\text { imunes ao controle le- } \\
\text { gislativo. O Congresso } \\
\text { possui sérias limitações } \\
\text { para o exercício da ac- } \\
\text { countability. }\end{array}$ & $\begin{array}{l}\text { O Congresso possui um } \\
\text { papel formal para a moni- } \\
\text { toria da atividade militar. } \\
\text { Entretanto, os deputados } \\
\text { e senadores são frequen- } \\
\text { temente limitados nessa } \\
\text { tarefa pela falta de prepa- } \\
\text { ro ou interesse dos civis, } \\
\text { assim como pela impo- } \\
\text { sição dos interesses das } \\
\text { Forças Armadas nesse } \\
\text { campo. }\end{array}$ & $\begin{array}{l}\text { Comitês Parlamentares } \\
\text { normalmente processam } \\
\text { casos de violações de di- } \\
\text { reitos humanos, autori- } \\
\text { zam promoções militares } \\
\text { e possuem a prerrogativa } \\
\text { de solicitar a presença } \\
\text { dos Comandantes Mili- } \\
\text { tares no Congresso para } \\
\text { esclarecer questões, as- } \\
\text { sim como decidir sobre } \\
\text { a alocação do orçamento. }\end{array}$ \\
\hline $\begin{array}{l}\text { Controle do } \\
\text { Judiciário }\end{array}$ & $\begin{array}{l}\text { Cortes militares normal- } \\
\text { mente processam pessoal } \\
\text { militar. Civis podem ser } \\
\text { julgados por cortes mili- } \\
\text { tares. }\end{array}$ & Misto. & $\begin{array}{l}\text { Cortes civis normal- } \\
\text { mente tratam de todas } \\
\text { as violações de direitos } \\
\text { humanos. Os civis não } \\
\text { são julgados por cortes } \\
\text { militares. }\end{array}$ \\
\hline $\begin{array}{l}\text { Sociedade } \\
\text { Civil (ONGs, } \\
\text { academia, } \\
\text { mídia, } \\
\text { movimentos } \\
\text { sociais e } \\
\text { associações da } \\
\text { comunidade) }\end{array}$ & $\begin{array}{l}\text { A sociedade civil é ex- } \\
\text { cluída do processo de } \\
\text { monitoramento do com- } \\
\text { portamento das Forças } \\
\text { Armadas. Intimidação } \\
\text { de agentes do Estado } \\
\text { e segredo institucional } \\
\text { restringem a mobilização } \\
\text { social nessa matéria. }\end{array}$ & $\begin{array}{l}\text { Monitoria do comporta- } \\
\text { mento dos militares com } \\
\text { limitada informação. Sua } \\
\text { ação restringe-se à "de- } \\
\text { núncia", com pouca re- } \\
\text { percussão sobre o sistema } \\
\text { político. }\end{array}$ & $\begin{array}{l}\text { Monitora e participa } \\
\text { da discussão de tópicos } \\
\text { centrais relacionados à } \\
\text { política de defesa. O Con- } \\
\text { gresso e o Executivo são } \\
\text { particularmente sensíveis } \\
\text { às contribuições e denún- } \\
\text { cias de organizações da } \\
\text { sociedade civil na área de } \\
\text { direitos humanos. }\end{array}$ \\
\hline
\end{tabular}

Fonte: elaborado pela autora a partir da revisão da literatura especializada. 


\section{Quadro 2 \\ Classificação do Controle Civil no Brasil}

\begin{tabular}{|l|l|}
\hline Regras Profissionais & 2 \\
\hline Ministério da Defesa & 2 \\
\hline Controle Legislativo & 2 \\
\hline Controle Judiciário & 2 \\
\hline Sociedade Civil & 2 \\
\hline
\end{tabular}

Fonte: elaborado pela autora a partir de entrevistas com militares, burocratas e membros da sociedade civil mencionados nesse artigo. Para mais informações, consultar Passos (2018).

Entretanto, à medida que a democratização se aprofundou, as autoridades políticas contestaram alguns privilégios das instituições militares e criaram órgãos liderados por civis que substituíram o Conselho Nacional de Segurança e o Sistema Nacional de Informações (SNI) (Hunter 1995, 427). Em governos posteriores, encabeçados pelo Partido dos Trabalhadores (PT), as autoridades políticas institucionalizaram o comando exercido pelo Ministro da Defesa sobre os Comandantes da Marinha, da Força Aérea e do Exército (2007-2010), assim como estabeleceram uma Comissão da Verdade em 2012 para a investigação de violações de direitos humanos que foram cometidas entre 1946 e 1988 (Passos 2014). Essa decisão afetou, de maneira crítica, o interesse corporativo do oficialato. Em fevereiro de 2010, o General Maynard Marques de Santa Rosa (Chefe de Departamento de Pessoal do Exército) realizou um discurso, em cerimônia militar, criticando a política de direitos humanos do governo, assim como a criação da Comissão Nacional da Verdade. Ele foi imediatamente removido da sua posição.

Recentemente, é necessário destacar que tal balanço foi alterado com a nomeação, pelo então presidente Michel Temer, de um General do Exército para liderar o Ministério da Defesa, em março de 2018, e o alargamento da jurisdição das cortes militares para processar violações de direitos humanos (Lei ${ }^{\circ}$ 13.491/2017). O Governo de Jair Bolsonaro manteve essa estratégia de inclusão das elites militares no processo decisório, mediante uma concessão histórica de cargos no governo. Foram nomeados 7 ministros militares, incluindo o General Fernando Azevedo e Silva no Ministério da Defesa. ${ }^{5}$ Entretanto, para efeitos da caracterização dos estudos de caso, trataremos especificamente do período compreendido entre 2010 e 2015, quando o Ministério da Defesa foi liderado por civis.

Em termos de doutrina militar, é importante notar que a sociedade civil participou de debates em seis estados, no ano de 2012, para consolidar a 
estratégia nacional que foi codificada no Livro Branco de Defesa e, quatro anos depois, na Estratégia de Defesa Nacional (EDN). Ambos os documentos são públicos e detalham os principais objetivos do Estado Brasileiro nas áreas política e estratégica de defesa, porém não abrangem o nível tático - o qual é rotulado como uma área de competência exclusiva das Forças Armadas. Isso nos permite classificar as normas profissionais como um controle civil limitado.

Nas esferas do Poder Judiciário, do Poder Legislativo e do Ministério da Defesa, existem limites relevantes para a consolidação de um controle civil extensivo. A jurisdição das cortes militares, conforme mencionado anteriormente, foi recentemente ampliada, abrangendo qualquer crime cometido por pessoal militar. As Forças Armadas brasileiras continuam a desfrutar de um limitado controle parlamentar sobre a alocação do orçamento de defesa (Limongi and Figueiredo 2002, 151). Além disso, os políticos frequentemente apenas "carimbam" os valores que foram acordados pelo Presidente, pelo Ministro da Defesa e pelos comandantes militares, omitindo-se do debate político sobre gastos em defesa (Zaverucha and Rezende 2009, 424).

Em relação às promoções militares, os resultados são mistos. Desde 2010, o Ministro da Defesa recomenda generais para a promoção, ao invés dos comandantes militares, porém o Legislativo não exerce nenhuma interferência em confirmar tais nominações, as quais dependem exclusivamente da aprovação presidencial (Lemos 2005, 82). No que diz respeito à sociedade civil, o papel de monitoramento das atividades militares é limitado, pela sua própria natureza, à denúncia sobre desvios de conduta quando este já ocorreu. Ou seja, esse tipo de controle social abrange principalmente o período posterior à conclusão da atividade do agente militar, o que nos leva a caracterizá-lo como uma forma de controle civil limitado.

A classificação ficará mais clara na próxima seção, na qual analisamos o funcionamento dos mecanismos de controle durante as operações para a garantia da lei e da ordem na cidade do Rio de Janeiro entre os anos de 2010 e 2015. Adotamos uma análise "de cima para baixo" sobre a política de intervenção dos militares na segurança pública, que busca verificar como as decisões políticas são negociadas ou contestadas no nível local (Bernazzoli and Flint 2010). Primeiro, analisamos os níveis superiores de controle, incluindo o Ministério da Defesa e o Poder Judiciário. A seguir, tratamos dos mecanismos locais, incluindo as organizações não-governamentais e as associações locais.

Adicionalmente, iremos analisar os aspectos institucionais do controle sobre os militares, que não estão relacionados aos aspectos formais, mas sim àqueles traços informais deste controle — os quais são compartilha- 
dos pela sociedade e reproduzidos fora dos canais oficiais (Helmke and Levitsky 2006). Algumas das questões que essa seção visa a responder são: Como as autoridades políticas interpretam a natureza do controle civil: como resultado de uma relação de comando ou de uma barganha entre civis e oficiais militares? Sobre esse aspecto, qual o nível de autonomia que deve ser concedido às Forças Armadas? E como essas concepções afetam o emprego dos meios de violência em cada operação analisada?

\section{CONTROLE CIVIL LIMITADO NO RIO DE JANEIRO}

\section{Ministério da Defesa}

A democracia é um regime político que não admite que outro grupo possua maior legitimidade que a vontade do povo para governar (Fitch 1998, 40). Consequentemente, do ponto de vista normativo, esse tipo de sistema político exige a eliminação de áreas de autonomia dos militares. O Ministério da Defesa representa a instituição, por excelência, na qual a subordinação dos militares às autoridades eleitas se concretiza. Nesse sentido, o pesquisador Samy Cohen nota que essa instituição representa um canal de comunicação e de negociação entre interesses corporativos e políticas governamentais. $\mathrm{O}$ autor agrega que

Ele [o Ministro] é responsável por convencer os comandantes militares sobre orientações governamentais pouco populares; por outro lado, comunica as demandas dos militares ao Primeiro Ministro e aos membros do Parlamento quando as mesmas lhe parecem legítimas"(Cohen 2008, 24-25).

Entretanto, essa definição não responde ao dilema entre equilibrar controle civil com a manutenção de certo grau de autonomia institucional que é necessária para preservar o seu status de expertos no emprego da violência (Pion-Berlin 1992). Conforme Sapolsky, Gholz e Talmadge (2009, 91) argumentam, a sociedade permite que algumas profissões sejam autônomas, reconhecendo o valor adquirido com sua expertise. As Forças Armadas geralmente desfrutam de maior autonomia do que as outras profissões devido à natureza complexa da sua função na provisão da defesa nacional. Adicionalmente, a diferenciação de assuntos puramente profissionais de assuntos políticos é complexa (Pion-Berlin 1992, 97-98). Esse aspecto é particularmente importante durante intervenções militares na segurança pública, visto que o contato próximo entre civis e oficiais dilui as linhas que separam assuntos corporativos dos políticos. 
Comprovando a expectativa teórica sobre as dificuldades de prestação de contas das atividades militares, a pesquisa demonstra que o controle civil sobre as Forças Armadas brasileiras foi exercido principalmente antes das operações iniciarem nas favelas do Rio de Janeiro, através de um processo de barganha entre autoridades civis e autoridades militares. Durante a sua administração como Ministro da Defesa (2007-2011), Nelson Jobim planejou e implementou o que ele próprio definiu como uma divisão de trabalho entre autoridades políticas e militares do alto escalão. O ex-Ministro resumiu a orientação com as seguintes palavras: "A forma como faz [a operação] não é problema meu. Operacional e tático: eu não entrava nisso. Eles [oficiais militares] podiam me contar o que estavam fazendo, eu ouvia. Mas a decisão operacional era exclusivamente dos militares". ${ }^{6}$

Dentro da estrutura do Ministério, o SAJ (Serviço de Assessoria Jurídica) é encarregado de aconselhar os Comandantes Militares sobre a adequação de uma operação aos requisitos legais e constitucionais vigentes. Entretanto, essa tarefa enfrentou limitações. Uma vez que se inicia, os servidores responsáveis por conformar a operação de acordo com a lei são oficiais militares graduados em direito que permanecem na área e estão subordinados hierarquicamente aos comandantes militares. Portanto, o papel do SAJ é principalmente exercido antes do início das operações, e baseia-se de maneira intensa no conhecimento e na expertise dos oficiais militares. ${ }^{7}$ Consequentemente, ao invés de atuar como um órgão de controle externo, esse órgão atua como uma instância de assessoria que fornece segurança jurídica às Forças Armadas durante a operação.

No nível estadual, o Ministro da Defesa representa não tanto o governo central quanto os interesses dos comandantes militares, comunicando eventuais problemas durante as operações ao Secretário de Segurança Pública. ${ }^{8}$ Em entrevista com a autora, o ex-Ministro da Defesa Celso Amorim salientou que contatava o governador para reclamar sobre a ausência de policiais na área "O nosso pessoal primeiro se queixava que havia poucos policiais. De fato, houve poucos. E, de fato, isso dificultou a tarefa.”. Portanto, o Ministro da Defesa atua não somente como porta-voz das instituições militares, mas também incorpora disputas entre o governo central e o governo estadual.

Além disso, o Ministro da Defesa utilizou controles informais (por exemplo, chamadas telefônicas) para esclarecer situações ambíguas com o Comandante Militar da área ou com o General responsável pela operação - como um possível tiroteio na área ou um comportamento inadequado dos soldados. ${ }^{9}$ É importante ressaltar que informações sobre prisão, confronto com grupos criminosos e danos "colaterais" para os moradores são fornecidas pelos membros da Força de Pacificação. Essas infor- 
mações eram transmitidas ao Setor de Inteligência das operações para o Comandante Militar do Leste, que as encaminhava para o Comando de Operações Terrestres (COTER). O COTER envia o relatório final ao Ministro. ${ }^{10}$ Nesse sentido, as fontes de informação do Ministro são limitadas à perspectiva dos militares, o que pode gerar um viés a respeito do desenvolvimento da operação GLO.

O Ministro da Defesa é assessorado por oficiais militares e possui pouca interação com especialistas civis. Esse dilema é descrito por Janowitz como a competição entre o especialista e o não-especialista, visto que o militar tende a perpetuar uma jurisdição profissional exclusiva sobre questões relacionadas à guerra e à segurança interna (Janowitz 1960, 40). Essa dinâmica é tanto o resultado da demanda civil quanto da imposição militar. Por um lado, os civis reconhecem o seu limitado conhecimento sobre assuntos táticos e operacionais, delegando competências aos militares; por outro, estes buscam assegurar o mínimo de intrusão externa nos seus assuntos corporativos. Portanto, o Ministério da Defesa exerceu controle civil principalmente antes das operações GLO analisadas, ainda que algumas iniciativas informais tenham sido identificadas durante a operação.

\section{Poderes Judiciário e Legislativo}

Enquanto o Ministro da Defesa exerceu controle - em grande medida, antes do início da ação militar GLO nas favelas — houve algumas iniciativas dos Poderes Judiciário e Legislativo para monitorar a ação das Forças Armadas. Em novembro de 2010, a Procuradoria Regional dos Direitos do Cidadão criou um grupo de trabalho para acompanhar a operação nos Complexos do Alemão e da Penha até a sua conclusão em julho de 2012. Nesse contexto, as procuradoras que representavam a instituição mantinham encontros regulares com o Comandante Militar do Leste. Entretanto, essa iniciativa falhou em estabelecer uma comunicação direta com as associações de moradores, alegadamente devido à violência nas favelas. ${ }^{11}$

A Procuradoria Regional organizou uma audiência pública para discutir a operação nos Complexos da Penha e do Alemão, após representantes de associações de moradores e de organizações de direitos humanos contatarem a Procuradoria sobre casos de violência que eles não puderam comunicar ao ombudsman militar, à época instalado no $22^{\circ}$ Batalhão Militar da região.

Patrícia, uma mulher negra que atua pela defesa dos direitos humanos, cujo irmão sobreviveu à Chacina da Candelária em 1993, observou que um grupo de moradores que desejava participar da audiência pública enfrentou dificuldades para se locomover. No dia da audiência, um grupo de 
soldados inicialmente impediu que o grupo saísse de uma das favelas pertencentes ao Complexo do Alemão, considerando que o deslocamento de uma van com moradores de favelas para o centro da cidade era "suspeito". Ao notar a discriminação racial e econômica evidente na situação, Patrícia observou que os soldados apenas os autorizaram a deixar a favela depois que o Procurador contatou o Comandante Militar, explicando a situação: "Não queriam liberar as kombis porque achavam que podia ser protesto, achavam que podia ser não sei o quê, não sei o que lá. (...) era muita gente, né, morador de favela, saindo do Alemão, "vai fazer baderna, vai quebrar.."12

Após a conclusão da Audiência Pública, a Procuradoria Regional dos Direitos do Cidadão (PRDC) investigou seis casos de abuso da força envolvendo membros da Força de Pacificação, visto que a PRDC interpreta que os militares devem ser julgados pela justiça comum. ${ }^{13}$ Dessa maneira, o Judiciário foi ativado pela população como o que a literatura denomina "patrulha de polícia” (police patrol). Esse mecanismo é uma forma intrusiva de monitorar o agente para resolver problemas de delegação. Envolvem investigações sistemáticas sobre como e de que maneira o agente desempenha a sua tarefa (Kiewet and Mccubins 1991, 32).

Durante a primeira operação para a garantia da lei e da ordem (11/2010-06/2012), os casos de abuso da força que foram relatados pelas associações locais incluíram: 1) Uso alegado de força excessiva, como o uso de spray de pimenta e balas de borracha em um ambiente fechado contra moradores para reprimir uma festa não autorizada pelo Comando da Força de Pacificação em uma casa no Largo da Cruzeiro (05/11/2011). ${ }^{14}$ 2) Uso alegado de força excessiva durante uma busca à noite em um bar na mesma localidade (24/07/2011). Um morador perdeu completamente a visão de um dos olhos durante a intervenção. ${ }^{15} 3$ ) Ferimentos a uma garota que retornava para a escola durante confronto entre traficantes e uma patrulha do Exército. ${ }^{16}$ Um dos processos foi aberto após a Comissão de Direitos Humanos da Assembleia Legislativa, presidida à época pelo deputado do PSOL (Partido Socialismo e Liberdade) Marcelo Freixo, receber uma denúncia cidadã.

É importante ressaltar que investigações de cortes civis sobre pessoal militar geralmente enfrentam dificuldades para o processamento de denúncias cidadãs. Mesmo quando existe a possibilidade formal para fazê-lo, práticas informais e a falta de interesse político podem debilitar a investigação. Conforme a pesquisadora Ximena Suárez-Enríquez (2017) conclui, existem no mínimo três formas por meio das quais as autoridades militares podem obstruir ou atrasar investigações: 1) realizando uma investigação em paralelo, 2) quando oficiais limitam o acesso ao testemunho de pessoal militar e 3) quando pessoal militar dá falsos testemunhos. 
No segundo caso que foi iniciado pela PRDC, cortes militares conduziram um processo paralelo que inocentou a defesa das acusações, o que atrasou a investigação civil (que permanece até a presente data em aberto). Os outros dois processos, mencionados anteriormente, foram arquivados porque a) a vítima desistiu de comparecer à Corte para testemunhar ou b) os oficiais militares testemunharam que o uso da força era razoável, considerando a agressão e insultos das tropas e, portanto, inocentou a defesa da acusação de uso excessivo da força.

As dificuldades para monitorar as ações dos militares foram exacerbadas pela existência de uma limitada oposição partidária às estratégias implementadas pelo governo do estado para a segurança pública. Durante a operação no Alemão e na Penha, o Governador do PMDB (Partido do Movimento Democrático Brasileiro), Sérgio Cabral (01/2007-01/2011; 01/2011-03/04/2014) desfrutou de um amplo apoio na Assembleia Legislativa, incluindo o Presidente da Casa, Jorge Picciani (PMDB) (2003-2010, 2015-) (Guedes da Graça 2014). A coalizão que elegeu Sérgio Cabral para o segundo mandato abrangeu 15 partidos (incluindo o PT), correspondendo a 60 dos 70 deputados. ${ }^{17}$ Portanto, foi um governo, com ampla maioria no Legislativo, que solicitou o apoio das Forças Armadas na segurança em novembro de 2010 e, posteriormente, sustentou a sua prolongação. ${ }^{18}$

\section{ONGs e imprensa}

O uso de forças militares para a provisão de segurança provoca tensões com a rede existente de organizações locais nas favelas. Por exemplo, em apenas duas das 16 favelas que compõem o Complexo da Maré, Nova Holanda e Morro do Timbau, as seguintes organizações atuam: Observatório de Favelas, Redes da Maré, Luta pela Paz, Museu da Maré, CEASM (Centro de Estudos e Ações Solidárias da Maré) e associações de moradores. Próximo aos campi da UFRJ (Universidade Federal do Rio de Janeiro), muitos indivíduos com diploma superior organizam essas iniciativas da sociedade civil

Em comparação com as operações GLO nos Complexos da Penha e do Alemão, a ação militar foi mais contestada por cidadãos nessa região. No primeiro ano de operação, três protestos ocorreram no Complexo da Maré: no dia 15 de abril, no mês de julho e no dia 6 de setembro de 2015. Esses eventos foram explicitamente contra a presença de militares na área, como pode ser visto pelos flyers exibidos na Figura 1, a seguir. Em contraste, e mesmo que a operação tenha sido mais longa, apenas um protesto foi registrado em uma das favelas pertencentes ao Complexo do Alemão, no dia 
5 de setembro de 2011, um dia após um grupo de soldados interromper uma festa de rua e utilizar spray de pimenta e balas de borracha contra os participantes para dispersá-los.

No dia 31 de março de 2014, quatro dias antes do início da operação militar, um grupo de jovens moradores criou o grupo Maré Vive, uma plataforma online para cidadãos denunciarem atos de violência nas favelas. Ao menos duas hipóteses explicam o surgimento desse movimento. $\mathrm{O}$ primeiro foi o fracasso dos militares empregados em garantir a segurança física para os moradores no Complexo da Maré. Segundo, o ativismo histórico da região. Os criadores do Maré Vive não concordaram em dar uma entrevista para a autora, alegando questões de segurança. Em sua página do Facebook, um garoto negro segura um cartaz com um número de Whattsapp que recebe informações diárias dos residentes sobre pessoas desaparecidas e tiroteios. Diversos jovens, homens e mulheres, de diferentes favelas da Maré mencionaram, em entrevista, o uso desse site para verificar a existência de tiroteios e, desse modo, assegurar a sua segurança física antes de ingressar na favela. ${ }^{19}$ A criação do Maré Vive foi um dos mecanismos para monitorar a operação GLO após o seu início.
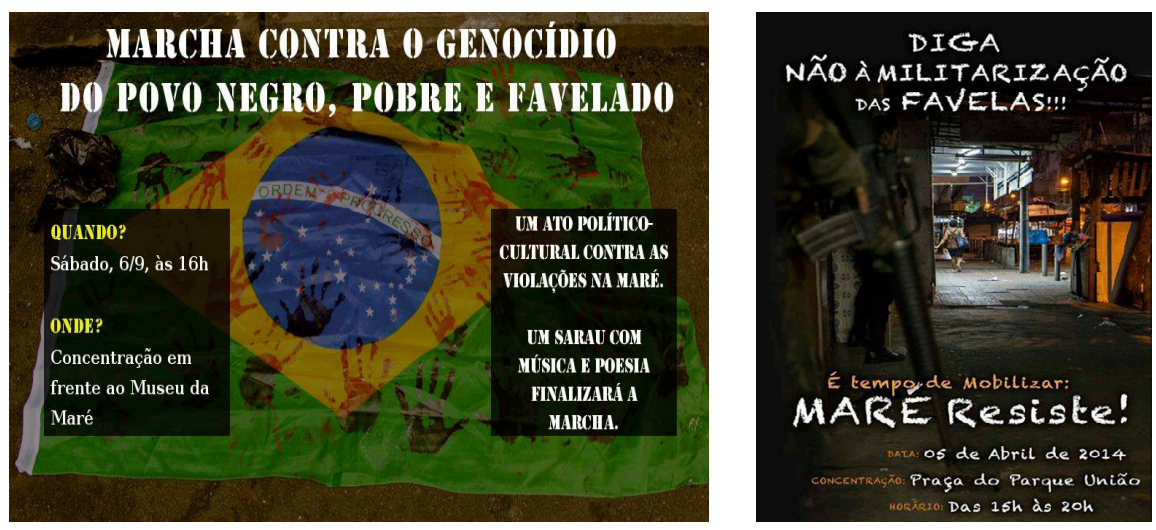

Figura 1 - Flyers dos Protestos contra a Presença das Forças Armadas nas favelas do Complexo da Maré, Rio de Janeiro.

Fonte: https://www.facebook.com/Marevive/

A sociedade civil adotou dois conjuntos de mecanismos durante as operações para a garantia da lei e da ordem. No nível individual, cidadãos engajam-se na monitoria incidental e documentam incidentes nos quais indivíduos sofrem abuso verbal ou físico dos soldados. Compartilha-se o vídeo com a família, amigos, organizações locais e a imprensa. Nesse caso, 
o vídeo é visto como uma prova objetiva do que ocorreu (ainda que seja apenas uma dimensão dos fatos) e como uma ferramenta para que oficiais militares prestem contas das suas atividades (Diamond 2010).

$\mathrm{O}$ caso do Wellington ${ }^{20}$ ilustra o uso da tecnologia nessa perspectiva. Wellington é um taxista que mora na vila do João. Ele relatou a sua experiência de filmar um grupo de soldados que estava em serviço, com a câmera do seu celular. Próximo à sua casa na Vila do João, Wellington observou um homem ser revistado três vezes seguidas por uma patrulha militar, à luz do dia. Na terceira vez, o homem, visivelmente irritado, começou a discutir com os soldados, que começaram a agredi-lo. Wellington imediatamente pegou o seu celular para filmar a cena. ${ }^{21}$ Entretanto, não é claro quão efetivos são os instrumentos de tecnologia para além do ato imediato de filmar infrações ou abusos, uma vez que estas já ocorreram. Nesse caso, Wellington foi levado à delegacia e, posteriormente, liberado. $\mathrm{O}$ evento permanece ignorado para a maior parte das pessoas fora do seu círculo de conhecidos.

Em relação às ações coletivas, as organizações locais atuaram antes e durante as operações com o objetivo de monitorar as ações. No Complexo da Maré, uma audiência pública foi organizada por iniciativa de um grupo de associações, incluindo o Observatório de Favelas, o Redes da Maré e associações de moradores. Conscientes das violações de direitos cometidas por agentes do Estado contra moradores de favelas, essa audiência teve por objetivo gerar um compromisso entre agentes do Estado para utilizar um nível de força mínimo e respeitar os direitos constitucionais dos moradores. No dia 4 de abril de 2014, Mariano Beltrame, Secretário de Segurança Pública do estado do Rio de Janeiro, e um representante da Comissão de Direitos Humanos da Assembleia Legislativa, assistiram à apresentação do documento "Princípio para a Ação", elaborado pelas organizações locais para orientar a atuação de agentes da segurança pública. ${ }^{22}$

Ainda que os resultados dessa iniciativa não sejam claros, um dos representantes do Observatório de Favelas notou que a organização encaminhou diversos casos de infrações, registrados pelos moradores, à Comissão de Direitos Humanos e à Procuradoria Estadual. Outro grupo, liderado pelo Redes e Comunidades Contra a Violência, reuniu advogados e ativistas para monitorar a operação na Maré. No Alemão, o grupo Voz das Comunidades, criado em 2009 por dois estudantes do Ensino Médio, utilizou as redes sociais para retratar a entrada das tropas militares na área. ${ }^{23}$ É notório que o Complexo da Maré possui uma rede robusta de organizações da sociedade civil, tendo desenvolvido formas de denunciar violações e infrações ex-ante e ex-post. Muitos casos foram retratados em meios de imprensa alternativa, porém estiveram limitados à "denúncia”, havendo dificuldades em comover a opinião pública no Rio de Janeiro. 


\section{Quadro 3}

Controle Civil Durante as Operações no Rio de Janeiro

\begin{tabular}{|c|c|}
\hline $\begin{array}{l}\text { Controle Civil } \\
\text { Durante a Operação }\end{array}$ & $\begin{array}{l}\text { Rio de Janeiro } \\
(12 / 2010-06 / 2012) ;(04 / 2014-03 / 2015)\end{array}$ \\
\hline $\begin{array}{l}\text { Normas } \\
\text { Profissionais }\end{array}$ & $\begin{array}{l}\text { Documento Público negociado entre o Ministro da Defesa e os } \\
\text { Comandantes Militares. Aprovado por um advogado (civil) (2) }\end{array}$ \\
\hline $\begin{array}{l}\text { Ministro da Defesa } \\
\text { Civil }\end{array}$ & $\begin{array}{l}\text { Ex-ante. Controle limitado durante a operação (depende de inicia- } \\
\text { tivas informais) (2) }\end{array}$ \\
\hline $\begin{array}{l}\text { Assembleia } \\
\text { Legislativa }\end{array}$ & $\begin{array}{l}\text { Algumas iniciativas da Comissão de Direitos Humanos. O partido } \\
\text { do governo possui maioria qualificada (1) }\end{array}$ \\
\hline Poder Judiciário & $\begin{array}{l}\text { As autoridades políticas não intervêm no monitoramento; rela- } \\
\text { ções cooperativas com os comandantes militares (baseiam-se em } \\
\text { expertise e informação); prerrogativa de iniciar processo legal a } \\
\text { partir de denúncias cidadãs (porém limitada pela jurisdição mi- } \\
\text { litar) (2) }\end{array}$ \\
\hline $\begin{array}{l}\text { Ativismo da } \\
\text { Sociedade Civil }\end{array}$ & $\begin{array}{l}\text { Protestos contra a intervenção militar são restritos às favelas ocu- } \\
\text { padas pelas Forças Armadas. Audiências públicas são organizadas } \\
\text { por grupos sociais. Visibilidade de comportamento desviante ape- } \\
\text { nas em meios alternativos de informação. (2) }\end{array}$ \\
\hline $\begin{array}{l}\text { Configuração } \\
\text { Institucional }\end{array}$ & $\begin{array}{l}\text { Controle Limitado (autoridade compartilhada na segurança pú- } \\
\text { blica com espaços de autonomia militar) }\end{array}$ \\
\hline
\end{tabular}

Fontes: elaborado pela autora a partir de entrevistas com militares, burocratas e membros da sociedade civil mencionados nesse artigo. Para mais informações, ver Passos (2018).

A análise dos mecanismos institucionais que atuam para o monitoramento e para a prestação de contas das atividades militares no âmbito doméstico assinalam que eles atuam principalmente no período ex-ante. Isto é, antes do início da operação, o que implica a delegação das áreas tático e operacional para os comandantes militares. Esse é o caso do Ministério da Defesa e da produção de normas profissionais. Demonstramos como a consolidação do controle civil expansivo enfrenta desafios nesse campo, visto que existe uma tensão entre a necessidade de prestação de contas e a continuidade de áreas de expertise que são próprias da atuação das Forças Armadas.

Por sua vez, tanto no âmbito do Poder Judiciário quanto do Poder Legislativo, destacamos algumas iniciativas que foram tomadas para garantir a responsividade dos militares e, em alguns casos, a punição de desvios de conduta - ambas as dimensões, conforme assinalamos no início do artigo, integram o conceito de accountability. No entanto, esses controles civis são limitados pelo escopo da jurisdição militar, que está facultada a processar os militares quando cometem infrações em serviço. Portanto, no que diz respeito à existência de controles do tipo intrusivo, 
como patrulhas de polícia (Kiewiet and McCubbins 1991), as iniciativas são bastante restritas.

Por último, salientamos que as operações GLO podem enfrentar oposição, quando não atingem o objetivo de assegurar a segurança física dos moradores, por parte das associações locais da sociedade civil. Essas iniciativas atuam como alarmes de incêndio, denunciando desvios e violações uma vez que tenham ocorrido. É necessário salientar que, como as atividades militares na segurança pública são implementadas em regiões da periferia — que já são tradicionalmente excluídas do sistema político e carecem de serviços públicos - essa forma de controle da operação é limitada pelas dinâmicas de exclusão social e econômica que subjazem a relação entre classes populares e Estado. Portanto, as dificuldades para o exercício de controles civis institucionais sobre as operações GLO incentiva a reprodução de um Estado de direito desigual, contribuindo para a consolidação de uma democracia de baixa qualidade.

\section{CONCLUSÃO}

A pesquisa nos permite concluir que houve uma forma limitada de controle civil durante as operações GLO nas favelas do Rio de Janeiro conduzidas entre 2010 e 2015. No que tange às instituições, o controle civil exercido pelo Ministro da Defesa está concentrado antes do início das operações. Visto que o Ministro é assessorado por pessoal militar, informações que ultrapassem a perspectiva das Forças Armadas são limitadas nesse âmbito.

A divisão de trabalho concebida pelo Ministro da Defesa à época entre autoridades civis e militares indica uma relação de negociação, ao invés de comando, entre militares e civis, o que, por sua vez, contribui para a manutenção de áreas de autonomia militar uma vez que a operação inicia. Especificamente, políticos e membros do Judiciário dependem intensamente de informações fornecidas pelos oficiais militares para monitorar as operações. Ao mesmo tempo, é certo que a necessidade de controles sobre as atividades domésticas dos militares enfrenta dificuldades pela existência de áreas de expertise, categorizadas como tático e operacional, que são próprias das Forças Armadas.

A ausência de mecanismos formais durante a operação é, em parte, equilibrada pelo monitoramento informal exercido pelo ministro, através de contato telefônico ou de reuniões com os comandantes militares, e pela atuação das organizações locais da sociedade civil. Em relação às iniciativas da sociedade civil, houve diferentes iniciativas da comunidade para monitorar as atividades militares ou para pressionar a Força de Pacificação, 
quando existiu algum desvio por parte dos militares. No entanto, por se tratar de ações promovidas pelas classes populares, as iniciativas carecem de maior integração com o sistema político.

Por último, o controle Legislativo e o controle Judiciário existem, mas são limitados pela jurisdição militar, que processa os casos de desvios de conduta dos militares em ação. Em conclusão, a pesquisa indica a existência de um controle civil antes da operação militar que se estende, de maneira limitada, à implementação da mesma. Isso debilita a prestação de contas dessas atividades e, especificamente, à punição de desvios de conduta. Nesse sentido, sugere-se ampliar os mecanismos de controle, uma vez que uma operação militar se inicia, além de qualificar civis para a atuação no Ministério da Defesa. Essas questões ganham relevância em um contexto no qual a intervenção dos militares para enfrentar a insegurança pública tem se tornado uma opção recorrente para os tomadores de decisão.

\section{AGRADECIMENTOS}

Esse artigo baseia-se em uma seção da minha tese de doutorado "The Military Mystique: Democracies and the War on Crime in Brazil and Mexico”, defendida em outubro de 2018 na Sciences Po Paris. Agradeço ao professor Olivier Dabène, que orientou a tese, assim como aos professores membros da banca de doutorado: Carlos Arturi, que inspirou a minha escolha pelo tema das relações civis-militares desde a graduacão, Leonardo Avritzer, Camille Goirand, David Pion-Berlin e Laurent Gayer. Também gostaria de agradecer aos comentários dos revisores anônimos dessa revista. A realização dessa pesquisa foi financiada através de uma bolsa de doutorado pleno no exterior da Coordenação de Aperfeiçoamento de Pessoal de Nível Superior (CAPES), Ministério da Educação, número do processo 04636-14-3. A pesquisa de campo no Brasil foi financiada pela École Doctorale da Sciences Po Paris.

\section{REFERÊNCIAS}

Aguero, Felipe. 1992. "The Military and the Limits to Democratization in South America." In Issues in Democratic Consolidation: The New South American Democracies in Comparative Perspective, organizado por Scott Mainwaring, Guillermo O'Donnell, and J. Samuel Valenzuela, 153-99. Notre Dame: University of Notre Dame Press.

1995. Soldiers, Civilians and Democracy: Post-Franco Spain in Comparative Perspective. Baltimore: John Hopkins University. 
Arturi, Carlos S. 2001. "O Debate Teórico Sobre Mudança de Regime Político: O Caso Brasileiro." Revista de Sociologia e Política no. 17, 11-31. https://doi. org/10.1590/S0104-44782001000200003.

Bernazzoli, Richelle M., and Colin Flint. 2010. "Embodying the Garrison State? Everyday Geographies of Militarization in American Society.” Political Geography 29 no. 3, 157-66. https://doi.org/10.1016/j.polgeo.2010.02.014.

Born, Hans. 2006. "Democratic Control of Armed Forces. Relevance, Issues and Research Agenda." In Handbook of the Sociology of the Military, organizado por Giuseppe Caforio, 151-66. New York: Springer. https://doi.org/10.1007/0-38734576-0.

Bovens, Mark. 2007. "Analysing and Assessing Accountability: A Conceptual Framework." Ssrn 13 no. 4, 447-68. https://doi.org/10.1111/j. 1468-0386.2007.00378.x.

Bruneau, Thomas C. 2001. "Ministries of Defense and Democratic Civil-Military Relations." Monterey, California: The Center for Civil-Military Relations. Naval Postgraduate School. https://doi.org/10.1007/0-306-48056-5_1.

Bruneau, Thomas C., and Florina Cristiana Matei. 2008. "Towards a New Conceptualization of Democratization and Civil-Military Relations." Democratization 15 no. 5, 909-29. https://doi.org/10.1080/13510340802362505.

Cohen, Samy. 2008. "Le Pouvoir Politique et l'Armée." Pouvoirs 125, 19-28.

Dahl, Robert Alan. 1973. Poliarchy. Participation and Opposition. 4. ed. New Haven and London: Yale University Press.

Diamint, Rut. 2015. "A New Militarism in Latin America." Journal of Democracy 26 no. 4, 155-68. https://doi.org/10.1353/jod.2015.0066.

Diamond, Larry. 2010. "Liberation Technology." Journal of Democracy 21 no. 3, 69-83. https://doi.org/10.1353/jod.o.0190.

Diamond, Larry, Marc F. Plattner, Yun-han Chu, and Hung-mao Tien, eds. 1997. Consolidating the Third Wave Democracies. Themes and Perspectives. Baltimore, Maryland: The Johns Hopkins University Press.

Feaver, Peter. 2003. Armed Servants. Agency, Oversight, and Civil-Military Relations. Cambridge, Massachusetts, and London, England: Harvard University Press.

Fitch, Samuel J. 1998. The Armed Forces and Democracy in Latin America. Baltimore, Maryland: The Johns Hopkins University Press. 
Fuccille, Luiz Alexandre. 2006. "Democracia e Questão Militar: A Criação do Ministério da Defesa no Brasil." Instituto de Filosofia e Ciências Humanas, Tese de Doutorado, Universidade Estadual de Campinas (Unicamp).

Garreton, Manuel Antonio. 1989. "La Relación Entre Transición y Consolidación: Los Enclaves Autoritarios." In La Posibilidad Democratica En Chile, 1. ed., 51-63. Chile: FLACSO.

Geisser, Vincent, Olivier Dabène, e Gilles Massardier. 2008. "La Démocratisation Contre La Démocratie." In Autoritarismes Démocratiques. Démocraties Autoritaires Au XXI Siècle, organizado por Olivier Dabène et al., 7-26. Paris: Découverte Recherches.

Guedes da Graça, Luís Felipe. 2014. "Independência ou Irrelevância? Produção Legislativa e Vetos na Assembleia Legislativa do Estado do Rio de Janeiro (19832010)." Universidade do Estado do Rio de Janeiro.

Guittet, Emmanuel-Pierre. 2006. "Military Activities Within National Boundaries: The French Case." In Illiberal Practices of Liberal Regimes: The (in) Security Games, edited by Didier Bigo and Anastassia Tsoukala, 136-62. Paris: L’Harmatan.

Hassenteufel, Patrick. 2014. Sociologie Politique: L'Action Publique. 2. ed. Paris: Armand Colin.

Helmke, Gretchen, and Steven Levitsky. 2006. "Introduction." In Informal Institutions and Democracy. Lessons from Latin America, 1-32. Baltimore: The Johns Hopkins University Press.

Hunter, Wendy. 1995. "Politicians against Soldiers: Contesting the Military Postauthorization Brazil." Comparative Politics 27 no. 4, 425-43. https://doi.org/ papers2://publication/uuid/C134FD4E-3318-4EAB-8AD7-7339C62CD089.

Huntington, Samuel P. 1991. The Third Wave: Democratization in the Late Twentieth Century. Norman, Okla: University of Oklahoma Press.

Janowitz, Morris. 1960. The Professional Soldier. A Social and Political Portrait. Glencoe, Illinois: The Free Press.

Joo, Ruodolf. 1996. "The Democratic Control Of Armed Forces." Chaillot Paper 23 (February).

Kappeler, Victor E., and Peter B. Kraska. 2015. "Normalising Police Militarisation, Living in Denial.” Policing and Society 25 no. 3, 268-75. https://doi.org/10.1080 / 10439463.2013.864655. 
Kiewiet, D. Roderick, and D. McCubbins. 1991. The Logic of Delegation. Congressional Parties and the Appropriations Process. Chicago: The University of Chicago Press.

Lemos, Leany Barreiro de Sousa. 2005. "Controle Legislativo em Democracias Presidencialistas: Brasil e EUA em Perspectiva Comparada.” Instituto de Ciências Sociais, Tese de Doutorado, Universidade de Brasília (UnB).

Lima, Carlos Alberto de. 2012. Os 583 Dias da Pacificação dos Complexos da Penha e do Alemão. Rio de Janeiro: Agência 2A Comunicação.

Limongi, Fernando, and Argelina Figueiredo. 2002. "Em Busca Do Orçamento Perdido III." Insight Inteligencia 16, 145-56.

Mainwaring, Scott, Guillermo O'Donnell, and J. Samuel Valenzuela, eds. 1992. Issues in Democratic Consolidation: The New South American Democracies in Comparative Perspective. Notre Dame: University of Notre Dame Press.

Mainwaring, Scott, and Christopher Christoper Welna. 2003. Democratic Accountability in Latin America. Oxford Studies in Democratization. https://doi.org/ 10.1093/0199256373.001.0001.

Mares, David R. 2003. "U.S. Drug Policy and Mexican Civil-Military Relations: A Challenge for the Mutually Desirable Democratization Process." Crime, Law and Social Change 40 no. 1, 61-75.

O’Donnell, Guillermo. 1993. "On the State, Democratization and Some Conceptual Problems: A Latin American View with Glances at Some Postcommunist Countries." World Development 21 no. 8, 1355-69. https://doi.org/10.1016/ 0305-750X(93)90048-E.

P. Huntington, Samuel. 1957. The Soldier and the State. The Theory and Politics of Civil-Military Relations. Cambridge Massachussets: The Belknap Press of Harvad University Press.

Passos, Anaís Medeiros. 2014. "O Estado Das Relações Civis-Militares No Brasil: Um Estudo de Caso Sobre o Ministério Da Defesa (2007-2011).” Departamento de Ciência Política, Dissertação de Mestrado, Universidade Federal do Rio Grande do Sul.

2018. "The Military Mystique: Democracies and the War on Crime in Brazil and Mexico." Centre de Recherches Internationales, Tese de Doutorado, Sciences Po Paris. 
Pion-Berlin, D., ed. 2001. Civil-Military Relations in Latin America. New Analytical Perspectives. Chapel Hill and London: The University of North Carolina Press.

Pion-Berlin, David. 1992. "Military Autonomy and Emerging Democracies in South America." Comparative Politics 25 no. 1, 83-102.

Sapolsky, Harvey M., Eugene Gholz, and Caitlin Talmadge. 2009. US Defense Politics: The Origins of Security Policy. New York Oxford: Routledge Taylor and Francis Group. https://doi.org/10.4324/9780203892473.

Schedler, Andreas. 1999. "Conceptualizing Accountability.” In The Self-Restraning State: Power and Accountability in New Democracies, organizado por Andreas Schedler, Larry Diamond e Marc F. Plattner, 13-28. London: Lynne Rienner Publishers.

Schiff, Rebecca L. 2009. The Military and Domestic Politics: A Concordance Theory of Civil-Military Relations. New York: Routledge.

Schmitter, Phillippe, and Terry Lyn Karl. 1991. "What Democracy Is.. and Is Not.” Journal of Democracy 2 no. 3, 75-88.

Stepan, Alfred. 1988. Rethinking Military Politics. Brazil and the Southern Cone. New Jersey: Princeton University Press.

Suárez-Enríquez, Ximena. 2017. Overlooking Justice: Human Rights Violations Committed by Mexican Soldiers Against Civilians are Met with Impunity. Washington DC: Wola Advocacy for Human Rights in the Americas.

Trinkunas, Harold. 2005. Crafting Civilian Control of the Military in Venezuela: A Comparative Perspective. Chapel Hill and London: The University of North Carolina Press.

Urquhart, Cathy. 2017. "Grounded Theory Method." In Grounded Theory for Qualitative Research: A Practical Guide, 2-25. 55 City Road: Sage Publications.

Weffort, Francisco. 1988. "Por Que Democracia?" In Democratizando o Brasil, organizado por Alfred Stepan, 483-519. São Paulo: Paz e Terra.

Zaverucha, Jorge. 1994. Rumor de Sabres. Tutela Militar ou Controle Civil? São Paulo: Editora Ática.

Zaverucha, Jorge, and Flavio da Cunha Rezende. 2009. "How the Military Competes for Expenditure in Brasillian Democracy: Arguments for an Outlier." International Political Science Review 3 no. 4, 407-29.https://doi. org/10.1177/0192512109342689. 


\section{NOTAS}

1. No original: Quis custodiet ipsos custodes?

2. De acordo com Scott Mainwaring, a accountability não se limita a verificar a legalidade da ação dos atores estatais, mas também visa a monitorar o seu comportamento de modo geral. Nas suas palavras: "Servidores públicos e agências necessitam promover a prestação de contas política e jurídica de suas atividades públicas" (Mainwaring e Welna 2003, 11). Tradução da autora.

3. O Globo, "Ordens para ataques ao Rio continuam a partir de presídio", 26/11/2010. p. 14-15.

4. Em contraste, a Argentina estabeleceu um Ministério da Defesa em 1958; a Colômbia em 1965 e o Uruguai em 1935.

5. Os Ministérios que são ocupados por militares, durante a presidência de Jair Bolsonaro, são os seguintes: Ministério de Minas e Energia, Gabinete de Segurança Institucional, Ministério da Defesa, Ministério de Ciência e Tecnologia, Ministério da Infraestrutura, Ministério da Transparência e Controladoria Geral da União, Secretaria do Governo. Fonte: Agência Brasil, "Militares comandarão sete áreas no governo de Bolsonaro". Disponível em: http://agenciabrasil.ebc.com.br/politica/ noticia/2018-11/militares-comandarao-sete-areas-no-governo-de-bolsonaro. Acesso:

6. Entrevista com ex-Ministro da Defesa Nelson Jobim, 22/03/2016, São Paulo.

7. Entrevista com funcionário civil do Ministério da Defesa, 01/04/2016, Brasília.

8. Entrevista com oficial militar, 07/04/2016, Rio de Janeiro. Entrevista com oficiais militares do Ministério da Defesa, 16/05/2016, Brasília. Entrevista com General do Exército, 04/05/2016, Porto Alegre,

9. Entrevista com ex-Ministro da Defesa Celso Amorim, 23/03/2016, Rio de Janeiro.

10. Entrevista com ex-Ministro da Defesa Nelson Jobim, 22/03/2016, São Paulo. Entrevista com ex-Comandante Militar do Leste, General Adriano Pereira, 01/04/2016, Brasília. Entrevista com oficial militar, 01/03/2016, Rio de Janeiro.

11. Entrevista com Procuradora Aline Caixeta, 04/03/2016, Rio de Janeiro.

12. Entrevista com Patrícia, Redes e Comunidades Contra a Violência, 20/05/2016, Rio de Janeiro.

13. Entrevista com funcionário do Ministério da Defesa, 01/04/2016, Brasília.

14. Processo no 1.30.001.001715/2012 — 27. PFDC, Rio de Janeiro. 
15. Processo no 1.30.001.003330/2011-13. PFDC, Rio de Janeiro.

16. Processo no 1.30.001.004468/2011-30. PFDC, Rio de Janeiro.

17. CPDOC. Verbete Biográfico. Disponível em: http://www.fgv.br/cpdoc/acervo/dicionarios/verbete-biografico/sergio-de-oliveira-cabral-santos-filho..

18. Entretanto, a operação na Maré começou após Sergio Cabral renunciar ao cargo, alegadamente com objetivo de concorrer às eleições para senador - um plano que ele abandonou para apoiar o candidato Cesar Maia (DEM).

19. Entrevista com morador da Vila do João, 22/04/2016, Rio de Janeiro. Entrevista com moradora da Vila dos Pinheiros, 09/05/2016, Rio de Janeiro. Entrevista com moradora da Nova Holanda, 16/04/2016, Rio de Janeiro. Entrevista com moradora da Vila dos Pinheiros, 18/04/2016, Rio de Janeiro.

20. Nome fictício para preservar a identidade do entrevistado.

21. Entrevista com Wellington, da Vila do João, 28/09/2016, Rio de Janeiro.

22. Entrevista com Raquel Wiladino, Observatório de Favelas, 29/04/2016, Rio de Janeiro.

23. Entrevista com morador do Complexo da Penha, 15/04/2016, Rio de Janeiro 


\section{RESUMO}

$\mathrm{O}$ artigo analisa a accountability sobre as operações de garantia da lei e da ordem. A partir de entrevistas com tomadores de decisão e atores da sociedade civil, que foram codificadas e analisadas através do software Nvivo, a pesquisa conclui que o controle civil está concentrado antes do início das operações militares.

Palavras-chave: Controle Civil; Forças Armadas; Ministério da Defesa; Operação para a Garantia da Lei e da Ordem.

\section{ABSTRACT}

The paper analyses the accountability over operations to ensure law and order. Based on interviews with decision-makers and actors from civil society, that were codified and analyzed using software Nvivo, the research concludes that civilian control is mainly concentrated before the onset of military operations.

Keywords: Civilian Control; Armed Forces; Ministry of Defense; Operations to Ensure Law and Order. 